Portland State University

PDXScholar

Engineering and Technology Management

Faculty Publications and Presentations

$1-1-2013$

\title{
Applying Technology Forecasting to New Product Development Target Setting of LCD Panels
}

Dong-Joon Lim

Portland State University

Neil Runde

Portland State University

Timothy R. Anderson

Portland State University, tim.anderson@pdx.edu

Follow this and additional works at: https://pdxscholar.library.pdx.edu/etm_fac

Part of the Engineering Commons

Let us know how access to this document benefits you.

\section{Citation Details}

Lim, Dong-Joon; Runde, Neil; and Anderson, Timothy R., "Applying Technology Forecasting to New Product Development Target Setting of LCD Panels" (2013). Engineering and Technology Management Faculty Publications and Presentations. 18.

https://pdxscholar.library.pdx.edu/etm_fac/18

This Post-Print is brought to you for free and open access. It has been accepted for inclusion in Engineering and Technology Management Faculty Publications and Presentations by an authorized administrator of PDXScholar. Please contact us if we can make this document more accessible: pdxscholar@pdx.edu. 


\title{
Applying Technology Forecasting to New Product Development Target Setting of LCD Panels
}

\author{
Dong-Joon Lim, Neil Runde and Timothy R. Anderson
}

\begin{abstract}
This chapter illustrates the Technology Forecasting using Data Envelopment Analysis (TFDEA) process on Liquid Crystal Display (LCD) performance characteristics from 1997 to 2012. The objective of this study is to forecast future state-of-the-arts (SOAs) specifications as well as to diagnose past technological advancement of the LCD industry. Appropriate characteristics were determined from a group of LCD technologists. Data was gathered from public databases and outlying data points were cross-referenced as a validity check. The TFDEA process is defined and its application to the dataset is described in detail. The results not only provide information on how LCD industry has evolved but also provide an insight on future NPD targets.
\end{abstract}

\section{INTRODUCTION}

Since the 1970s, Liquid Crystal Display (LCD) technology moved from small displays such as watches to large scale televisions/public displays. As performance demands increased, demands on manufacturing managers to plan and deliver competitive products have also increased (Craig, 2004). As demand for mobile computing and high-definition video standards took hold, worldwide sales of LCD and plasma displays increased dramatically along with decreases in unit cost. At the same time, businesses began replacing Cathode Ray Tube technology-based computer monitors with LCD displays (Take, 2003). The range of display technology is vast and the technologies are ever changing (see Fig.1) (Takiguchi, 1999).

The increasing demands pressed flat panel manufacturers to invest in larger sizes, greater resolution, and color/contrast improvements. LCD manufacturers have planning teams to forecast future LCD performance characteristics to remain competitive. Marketing companies track LCD 
technology trends using internal analysis. Often, advancements are constrained by external issues (i.e., broadcast standard adoption rates) that inhibit throughput or manufacturing limitations. An example of this is how LCDs are cut from "mother glass" with well-defined size constraints and do not improve in size in a continuous fashion, but increase in a step-wise mode. Weight or power usage can be improved continuously (HP, 2008).

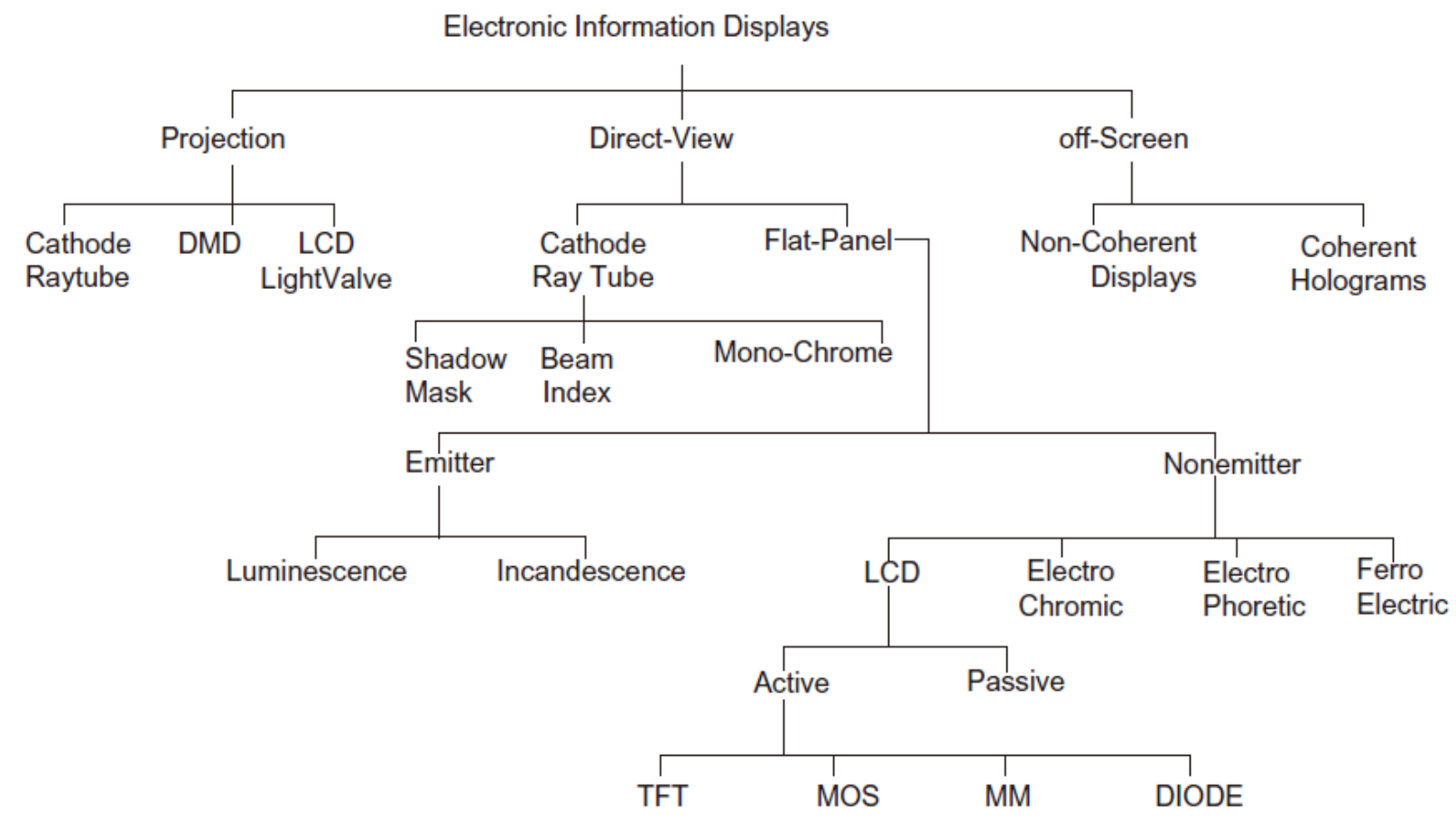

Figure 1 Electronic information display taxonomy

\section{ReSEARCh GOALS AND DESIGN CONSTRAINTS}

\section{A. Overall Research Aims}

The objective of this research is to determine changing patterns in the LCD image quality and physical device characteristics to forecast future values of similar products. 


\section{B. Projection Horizon Goals}

A "panel" of industry experts at a major flat panel manufacturer was interviewed to determine benchmark characteristics used for performance measurements. Modeling data to produce projections from 2012 to 2017 was determined by the best match to actual industry planning timeframes.

\section{Historical Data Boundary}

The history of LCD technologies goes back to the 1960s, however, 1997 was used as the starting point for this study because of the critical mass of larger ( $\left.>15^{\prime \prime}\right)$ LCD products were available in the market. This represented a point where LCD products moved beyond mobile computing and was of the most interest to our panel of experts.

\section{Type of Displays Considered}

As shown in Fig. 1, there is a range of technology options for electronic information displays. This chapter focuses on Direct-View, Flat Panel, Non-emitter, Active, and Thin-Film technologies which represent the bulk of high-definition televisions and computer monitors.

\section{E. Units Measured}

Working with industry experts, a list of fundamental attributes representing the core tradeoffs between products was developed. Data collected included the following:

- Release Date: (year)

- Screen Size: (inches) measured diagonally

- Bezel Size: (millimeter) derived by subtracting the beginning of the active area by the outside shell measurement

- Weight: (kilograms)

- Resolution: (pixels) horizontal times vertical resolution

- Viewing angle (degrees) 
- Contrast Ratio: (lumens) difference between 0-100\% energized pixel(s) (Learn About LCD TV and TFT LCD Displays, 2012).

\section{ANALYSIS}

\section{A. Data Gathering}

Panelook.com provided two-thirds of the research data and the rest of it were collected from online scanned manuals and various other sources including review sites. Statistical outliers were verified from secondary sources and removed if unconfirmed. In order to sample the full range of data, the authors searched criteria filtered on upper, middle, or low bounds on target characteristics. Derivative products of base-models that did not add to usable differences were removed from the dataset. There were 389 models, with diagonal screen sizes ranging from 14 to $108 \mathrm{uu}$, in the final data set from 20 manufacturers from 1997 to 2012 (see sample data in Table 1).

\section{B. Method}

Modern benchmarking analyses frequently use frontier analysis (or best practice) methods. The idea is to model the frontier of the technology rather than to model the average use of the technological possibilities (Bogetoft \& Otto, 2010). This approach has a strong advantage in learning from the best rather than being influenced by the inclusion of mediocre performers. Since its founding in 1978 (Charnes, Cooper, \& Rhodes, 1978), Data Envelopment Analysis (DEA), has been widely used as a frontier model for organizational benchmarking (Seiford, 1996). In 2001 it was extended to examine

Table 1 Sample data

\begin{tabular}{lllllllll}
\hline \multirow{2}{*}{ Manufacturer } & Product & $\begin{array}{l}\text { Release } \\
\text { Date }\end{array}$ & Screen Size & $\begin{array}{l}\text { Bezel } \\
\text { Size }\end{array}$ & Weight & Resolution & $\begin{array}{l}\text { Viewing } \\
\text { angle }\end{array}$ & $\begin{array}{l}\text { Contrast } \\
\text { Ratio }\end{array}$ \\
\hline NEC & EA192M & 1997 & 19 & 43.18 & 3.52 & $1,310,720$ & 170 & 1,000 \\
\multirow{2}{*}{ AUO } & T370HW01 V0 & 2004 & 37 & 75.44 & 10.00 & $2,073,600$ & 178 & 800 \\
\multirow{2}{*}{ Samsung } & LTI700HD01- & 2012 & 70 & 80.56 & 45.00 & $2,073,600$ & 178 & 2,400 \\
\hline
\end{tabular}


product-oriented performance by extending Moore's Law to a wider set of performance indicators and termed TFDEA (Technology Forecasting using DEA) (Anderson, Fare, Grosskopf, Inman, \& Song, 2002). It has since been applied to a wide range of industries including battle tanks (Kim, Kim, \& Kim, 2007), fighter jets (Inman, Anderson, \& Harmon, 2006), disk drives (Inman, 2004), telecommunications protocols (Anderson, Daim, \& Kim, 2008; Kim, Daim, \& Anderson, 2010; Lim, Anderson, \& Kim, 2012), and commercial airplanes (Lamb, Anderson, \& Daim, 2012).

TFDEA is able to leverage DEA's natural ability to handle rich models and applications in terms of flexibly handling both multiple inputs and multiple outputs. This is particularly important in the case of technology forecasting and new product development because the tradeoffs between product characteristics can vary by manufacturer, by market segment, and over time.

Figure 2 summarizes this model procedure. Briefly, $x_{i k}$ represents the $i$ th input and $y_{r k}$ represents the $r$ th output of technology $k$. The variables for the linear program underlying DEA are $\lambda_{j k}$ and $\emptyset_{k}^{t_{f}}$. The variable $\varnothing_{k}^{t_{f}}$ also serves as the objective function and represents the amount of output which should be generated by technology $k$ at time period $t_{f}$ if it were state-of-the-art at that time. The variables, $\lambda_{j k}$, describe how much of technology $j$ is used in setting a target of performance for technology $k$. Details of TFDEA procedures can be found in original research (Inman, 2004).

TFDEA can be conducted in two stages - model validation and actual extrapolation. Specifically, parameters to be used for the TFDEA model are determined in the first stage and future state-of-the-arts specifications of LCD products are estimated in the second stage.

\section{Model validation}

Fig. 3 illustrates the model validation process to determine an appropriate model for the LCD industry. Since TFDEA measures technological superiority using an efficiency framework, suitable characteristics of LCD products need to be determined as input(s) and output(s) values. As in other 


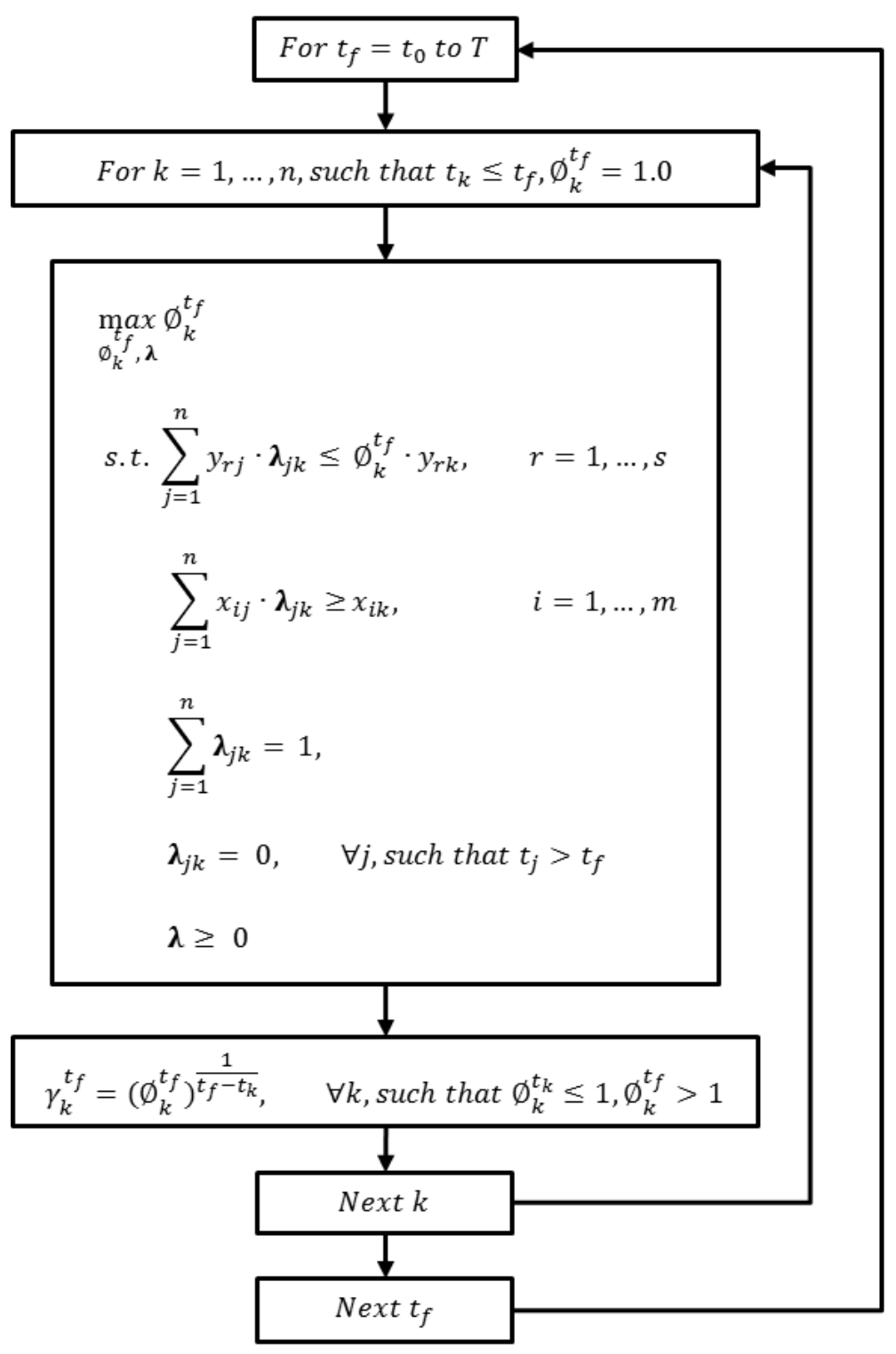

Figure 2 TFDEA process

recent forecasting techniques' applications, 'Backtesting,', was used to validate the effectiveness of forecasting model by running the current model up to a certain point in time and calculating how it would have performed had it actually been applied in the past. It was adopted to compare the accuracy of different models (Ro“sch, 2005). This backtesting procedure is analogous to using a holdout sample to validate a more traditional statistical model. Therefore, it is necessary to determine a proper point of time to divide the dataset. Finally, TFDEA parameters including orientation (input/output), returns to 
scale (RTS) (constant returns to scale/variable return to scale/nonincreasing return to scale/nondecreasing return to scale), and frontier (static/dynamic) are selected using this process.

Fig. 4 shows characteristics identified from the model validation process. As bezel size and weight tend to be proportional to screen size, normalized specifications, namely per-inch data, are used as inputs. For the output variables, screen size, pixel number, and contrast ratio were used to define the fundamental characteristics of display performance in terms of forecasting purpose.

Ideally, manufacturing cost should be included as an input but this is typically very difficult to include for many reasons:

- Each company has different ways of calculating cost and cost allocation methods.

- Cost is typically a rapidly decreasing value based on yield and learning, so a particular value in time would be needed.

- Different factories may be used for the same product with different cost functions.

- International currency fluctuations make it difficult to compare.

- Actual costs are confidential and therefore not available in industry publications.

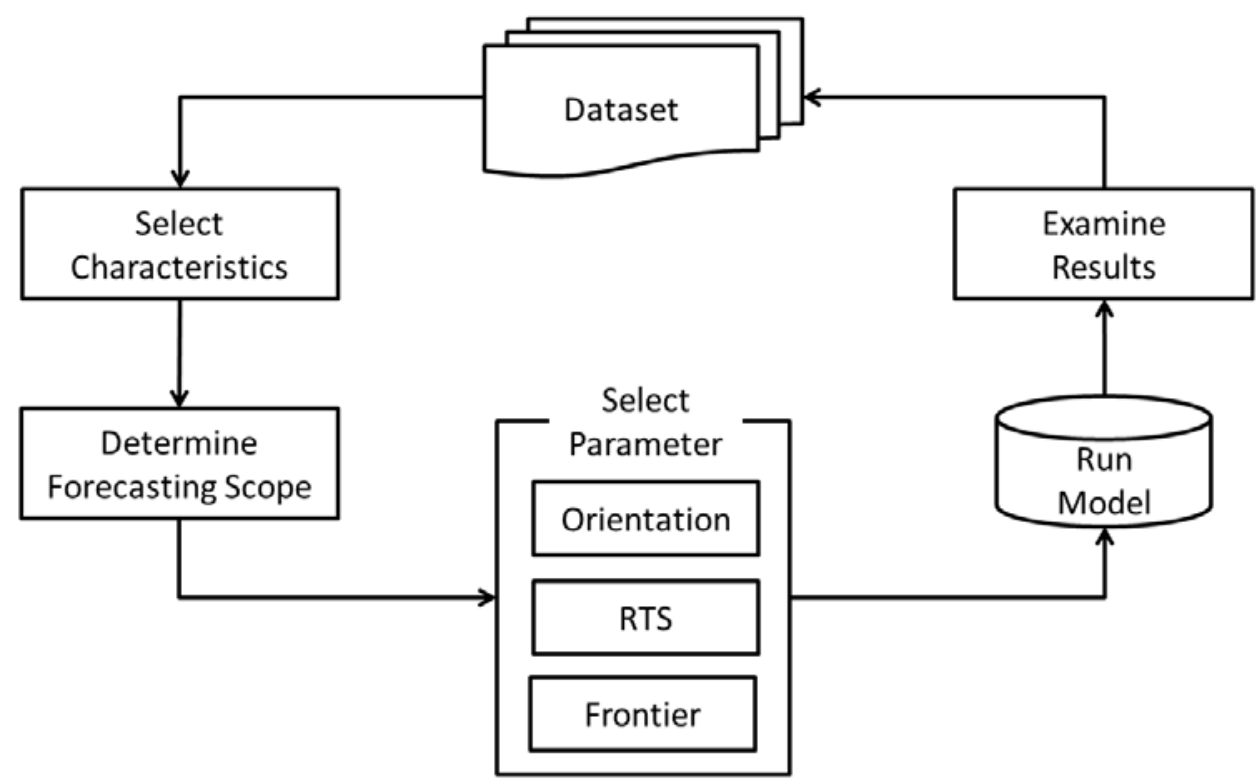

Figure 3 Model validation process 
In place of costs, a product price such as list price, manufacturer suggested retail price, or average selling price is sometimes used as a proxy for cost. Unfortunately, neither cost nor price was consistently available for the range of products.

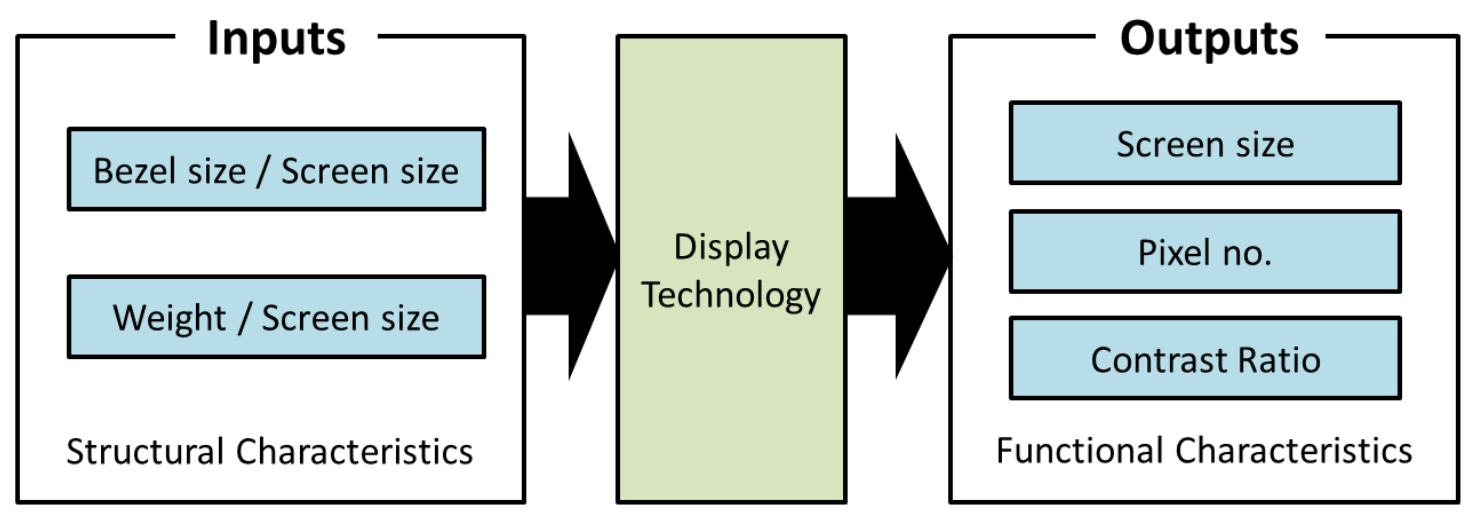

Figure 4 DEA model structure

Table 2 summarizes details of the analyzed model and results. A range of options was tested and the model was selected on the basis of characteristics of the application and accuracy in the validation stage.

TFDEA allows either static frontier or dynamic frontier to be used. The frontier year is a measure of the products that are being used to be compared against. For example, assume a 2005 LCD panel is being compared against panels from 2007 and earlier. The best comparisons for this product might be a combination of panels from 2006 and 2007. The static frontier year would use a fixed date of 2007 while a dynamic frontier year uses a combination of the dates of the products (2006 and 2007) such as 2006.5. In this application, a static frontier was used.

Table 2 Model results

\begin{tabular}{lllllll}
\hline Frontier Type & Orientation & 2nd Goal & Return to Scale & Avg RoC & Frontier Year & MAD \\
\hline Static & OO & N/A & VRS & 1.169682 & 2007 & 1.891382 \\
\hline Input(s) & Output(s) & $\begin{array}{l}\text { SOA products } \\
\text { at Release }\end{array}$ & $\begin{array}{l}\text { SOA products } \\
\text { on frontier }\end{array}$ & $\begin{array}{l}\text { RoC } \\
\text { contributors }\end{array}$ & $\begin{array}{l}\text { Release before } \\
\text { forecast }\end{array}$ & $\begin{array}{l}\text { Release after } \\
\text { forecast }\end{array}$ \\
\hline 2 & 3 & 78 & 7 & 30 & 9 & 76 \\
\hline
\end{tabular}


Orientation can be either input-oriented or output-oriented and can be best thought of as whether the primary goal is "input-reducing" or "outputaugmenting." While both screen performance and reducing bulkiness are important, in this time period, the LCD industry is better characterized as being driven by improving screen performance taking priority over making designs lighter and more compact. Therefore, an output orientation was selected for this application but a future study might find an input orientation a better fit if improving screen performance takes a back seat to bulkiness reduction. Hence, the model evaluates technologies based on how much advancement of outputs was produced using the same level of inputs.

DEA allows for various returns to scale assumptions. The most common are variable returns to scale (VRS) and constant returns to scale (CRS). Using CRS implies that for an actual product, a doubling of each of the inputs should result in a feasible product with double each of the outputs. In our application, doubling the inputs of the LCD panel does not correspond to a realistic design with double the outputs. Therefore, a VRS model was selected.

Average Rate of Change (Avg RoC) was found to be 1.169682, which means the overall performance of LCD products has improved by an average of $17 \%$ a year. Fig. 5 displays the annualized pattern of RoC over time. Gamma values indicate the progress in a product's performance in the current year as compared to the previous year. The rate fluctuates from year to year, and in each year we can see which products had the largest advance. From 1997 to 2012, LCD products from Samsung and LG dominated the rate-of-change list (2004 and 2005 technologies were annualized by other mediocre technologies). The years of 2001 and 2006 had the fastest rates of change. This can be explained by breakthrough technologies introduced during those times (see Table 3).

The frontier year was defined as 2007 which means the dataset was divided into two groups. The first had LCD panels included from 1997 up to and including 2007. The second set was used for 
backtesting to see how well the results from 1997-2007 forecasted the 2008-2012 data for validation purposes. This was a challenge due to the slowing rate of change shown in Fig. 5.

The mean absolute deviation, MAD, was 1.89 years. Hence, it is expected that there could be a 22-month error when this forecasting model is applied to LCD industry from 2007. Lower row of Table 2 shows the number of display technologies captured from the model; 2 inputs and 3 outputs characteristics were chosen for the model.

This model found that 88 out of 389 products were state-of-the-art when they were introduced. The non-state-of-the-art products are ones that were surpassed by a product or a combination of products.

Seven products were identified as state-of-the-art in 2007. Thirty products (out of 88 state-ofthe-arts) were taken into account when the model calculated the average rate of change because they used to be state-of-the art when they were released in the market but have been superseded by products released afterwards. In other words, TFDEA tries to capture this obsolescence process to measure the technology advancement.

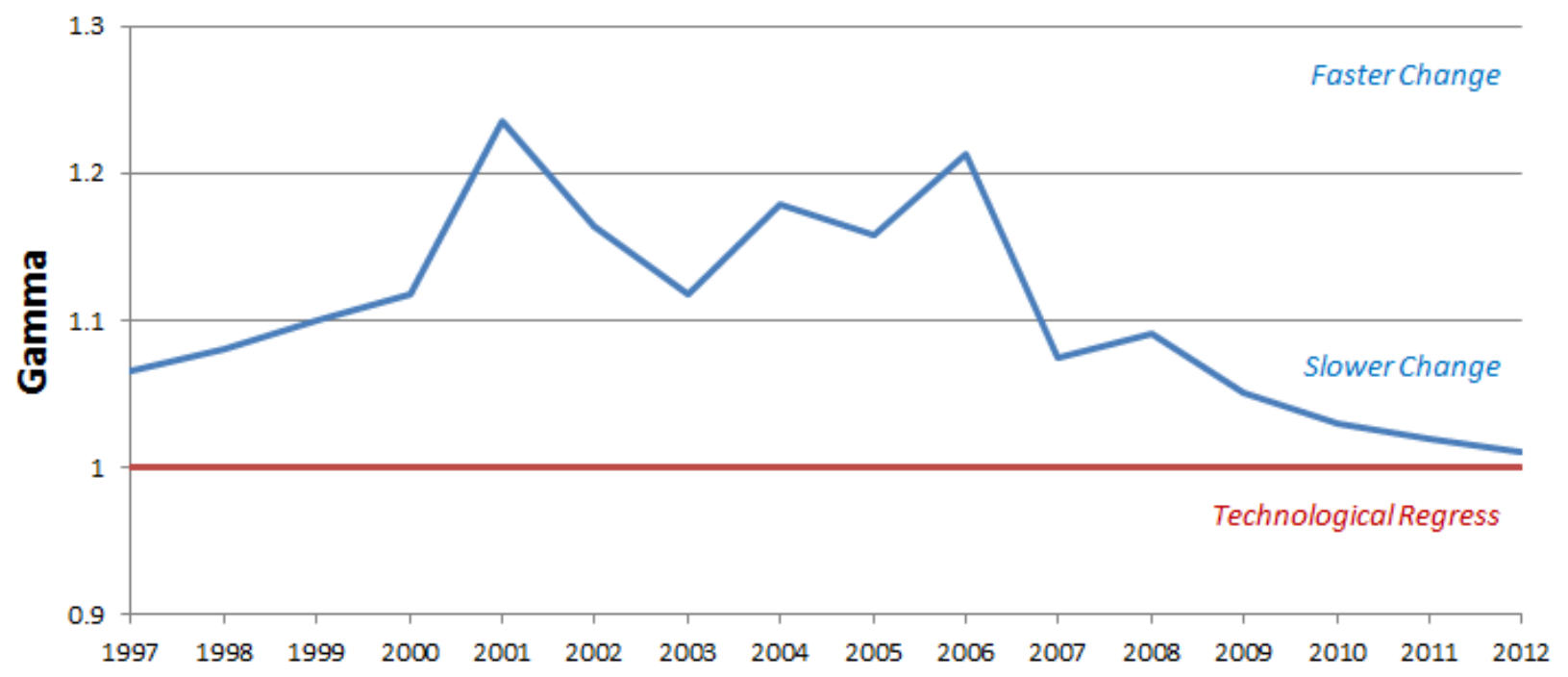

Figure 5 Annualized Rate of Change (RoC) 
Table 3 Top 5 Rate-of-Change products

\begin{tabular}{lllll}
\hline Rank & Release year & Model & Producer & Rate of Change \\
\hline 1 & 2006 & LM240WU2-SLB2 & LG & 1.555610 \\
2 & 2006 & LTM270M1-L01 & Samsung & 1.322629 \\
3 & 2005 & LTM240M1-L01 & Samsung & 1.303089 \\
4 & 2004 & LM300W01-A3 & LG & 1.245964 \\
5 & 2001 & SyncMaster 180T & Samsung & 1.236020 \\
\hline
\end{tabular}

The forecast result of backtesting shows that 9 products were released before the forecast, and 76 products were released after the forecast. This is consistent with the industry perception that the technology advancement has been slowing down (Tsai, 2012). Fig. 6 shows detailed results of this forecasting. Since the dataset was divided into two parts for backtesting, the model forecasted post2007 products based on the RoC identified from up-through-2007 technologies. As seen in the figure, some technologies are on the diagonal line which denotes perfect forecasting. Furthermore, most of forecasts are within 73 years range (note that mean absolute deviation is 1.891382, namely, 22 months).

Fig. 6 has four products with large forecast deviations from actual release dates; Table 4 provides more information on these products. The first model, "LTI460AL05," came out much earlier than expected and warranted attention. It had a $7.65 \mathrm{~mm}$ Bezel, which was much thinner than peers in $2009(50.90 \mathrm{~mm})$. The model forecasted that this level of technology (particularly a bezel this thin while maintaining the performance) would take more than 6 years from 2007 considering the average rate of change. However, it actually took only 2 years to introduce this product in the market. 


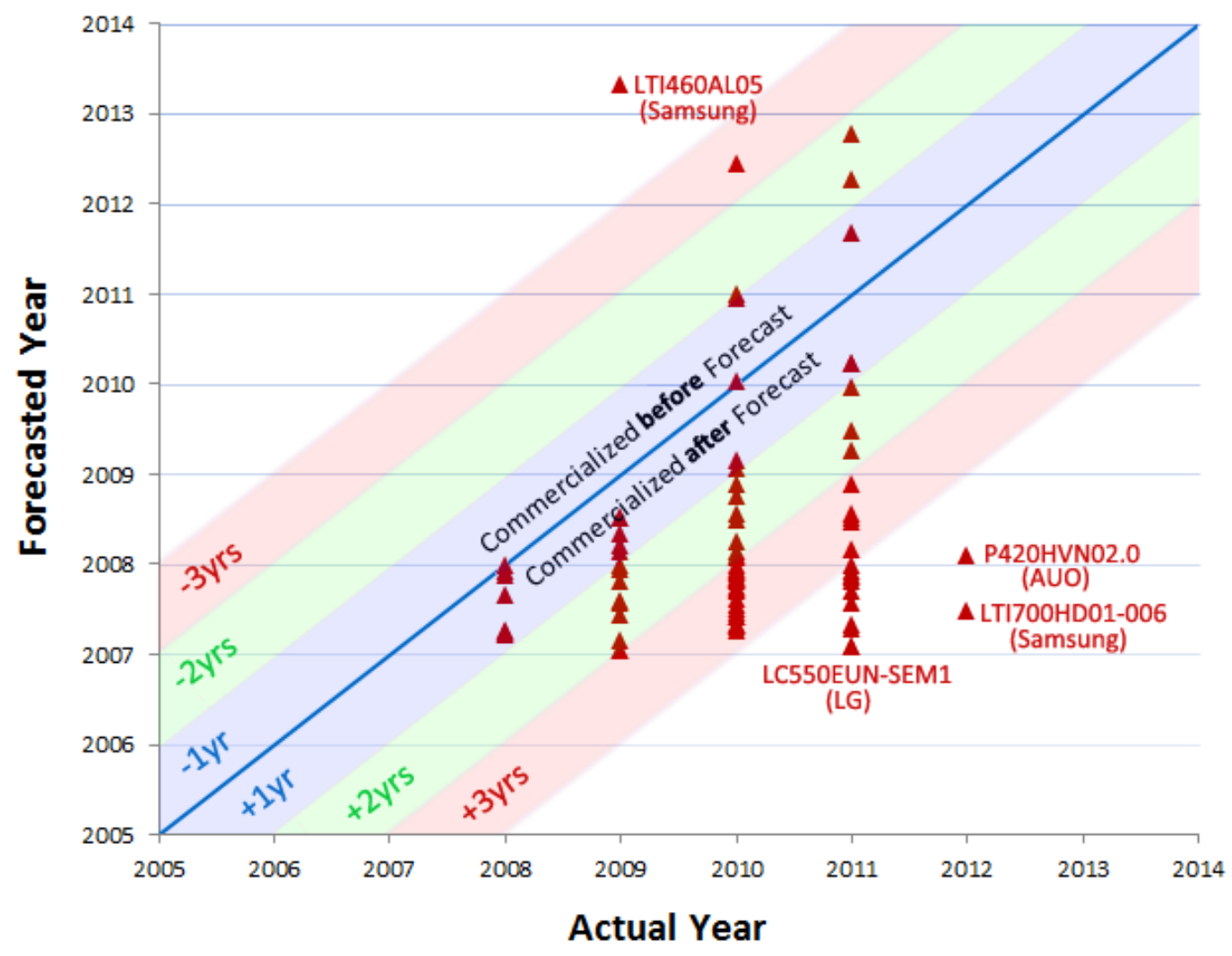

Figure 6 Forecasting results

On the other hand, three models came out later than were expected given their specifications. All three, "LC550EUN-SEM1," "P420HVN02.0," and "LTI700HD01-006," had relatively low contrast ratios (1400) and heavy screens $(0.64$ and 0.23$)$. Therefore, they were introduced later than forecasted by the model. However, this doesn't necessarily indicate that those were inferior products. Rather, manufacturers might have put more emphasis on other features that the forecasting model did not capture. For example, LTI700HD01-006 was a Digital Information Displays (DID) system which was aimed at outdoor digital signage and e-board applications requiring high reliability and robustness. In hindsight, it is not surprising that this product appears "obsolete" at time of release relative to the mainstream, indoor-oriented products. This product could be deleted from the analysis with no impact other than improving MAD (Table 4). 
Table 4 Examining outliers

\begin{tabular}{llllll}
\hline $\begin{array}{l}\text { Model } \\
\text { (Producer) }\end{array}$ & Super efficiency & Release year & Forecasted year & Error & Distinctive feature \\
\hline $\begin{array}{l}\text { LTI460AL05 } \\
\text { (Samsung) }\end{array}$ & 0.370872 & 2009 & 2013.33 & -4.33 & Ultra-thin Bezel \\
$\begin{array}{l}\text { LC550EUN-SEM1 } \\
\text { (LG) }\end{array}$ & 0.984897 & 2011 & 2007.10 & +3.90 & Low Contrast ratio \\
$\begin{array}{l}\text { P420HVN02.0 } \\
\text { (AUO) }\end{array}$ & 0.842535 & 2012 & 2008.09 & +3.91 & Heavy screen \\
$\begin{array}{l}\text { LTI700HD01-006 } \\
\text { (Samsung) }\end{array}$ & 0.927418 & 2012 & 2007.48 & +4.52 & Heavy screen \\
\hline
\end{tabular}

\section{NPD target setting}

With the model selected from validation process, future state-of-the-art products can be readily extrapolated. Since the model is using output oriented measurement, the simplest way is to multiply current output characteristics by average rate of change (1.169682) assuming constant input characteristics. Table 5 presents projected future state-of-the-arts from $2013(+1 \mathrm{yr})$ to 2017 ( $+5 \mathrm{yrs})$ with bezel size/screen size of 1.06 and weight/screen size of 0.28 . Conversely, if one wants to know when a specific level of technology can be realized as a state-of-the-art, expected time can be calculated by measuring gap between current level of technology and target specifications.

Table 5 Projected SOAs considering concurrent improvement

\begin{tabular}{llll}
\hline Year & $\begin{array}{l}\text { Screen size } \\
\text { (inches) }\end{array}$ & $\begin{array}{l}\text { Resolution } \\
\text { (megapixel) }\end{array}$ & $\begin{array}{l}\text { Contrast ratio } \\
\text { (luminance ratio) }\end{array}$ \\
\hline 2012 (current) & 41.25 & 2.679 & 2,133 \\
$2013(+1 \mathrm{yr})$ & 48.25 & 3.134 & 2,495 \\
$2014(+2 \mathrm{yrs})$ & 56.44 & 3.666 & 2,919 \\
$2015(+3 \mathrm{yrs})$ & 66.01 & 4.288 & 3,414 \\
$2016(+4 \mathrm{yrs})$ & 77.21 & 5.016 & 3,993 \\
$2017(+5 \mathrm{yrs})$ & 90.32 & 5.867 & 4,671 \\
\hline
\end{tabular}


In order to facilitate planning such as focusing $R \& D$ resources on certain output performance, further application that can consider trade-offs among the output characteristics is also possible. This uses the inverse-DEA process to place a virtual product on the frontier line with given efficient, namely, state-of-the-art products.

Table 6 presents diverse range of future state-of-the-arts specifications in 2017 ( $+5 \mathrm{yrs})$ from this process. As each column combination can represent state-of-the-art specification, a new product developer may be able to get benefit from this virtual design concept when he/she tries to propose new product design.

The trend toward larger screen sizes has been very visible throughout the consumer television industry over the last decade. Table 6 allows us to examine what is expected to be state-of-the-art in 2017 for these different screen sizes. The screen sizes are similar to what might be expected for highend home theater or certain commercial applications. The resolution values can be considered to be similar to certain video standards. For example, 1080p is currently the most common native resolution for HD televisions and is $1,920 \times 1,080$ or 2.07 megapixels. WQXGA is a higher resolution format currently used in computer monitors and is $2,560 \times 1,600$ or 4.1 megapixels. A less common format is referred to as $4 \mathrm{~K}$ and is $4,096 \times 3,072$ or 12.6 megapixels.

Table 6 indicates that for a 57" class HD television with resolution similar to WQXGA, the expected contrast ratio should be 11,320. Product designers could then evaluate their designs based on these specifications. If their contrast ratio is much greater, they are likely to have a product that outperforms competitors. If their contrast ratio is much lower, they should make clear why this product is different from the mass market - similar to the outdoor LCD panel discussed earlier. 
Table 6 Alternate 2017 SOAs projections

\begin{tabular}{lll}
\hline $\begin{array}{l}\text { Screen size } \\
\text { (inches) }\end{array}$ & $\begin{array}{l}\text { Resolution } \\
\text { (megapixel) }\end{array}$ & $\begin{array}{l}\text { Contrast ratio } \\
\text { (luminance ratio) }\end{array}$ \\
\hline & 2.189 & 11,385 \\
56.93 & 4.379 & 11,320 \\
& 6.568 & 10,509 \\
& 8.758 & 8,539 \\
& 10.947 & 6,678 \\
\hline 87.58 & 2.189 & 9,196 \\
& 4.378 & 9,130 \\
& 6.568 & 8,758 \\
& 8.758 & 8,101 \\
& 10.947 & 6,658 \\
\hline 09.47 & 2.189 & 6,787 \\
& 4,379 & 6,678 \\
& 6.568 & 6,131 \\
& 8.758 & 5,693 \\
131.37 & 10.947 & 5,036 \\
& 1.095 & 3,941 \\
& 2.189 & 3,613 \\
\hline
\end{tabular}

\section{LIMITATIONS AND FUtURE RESEARCH}

Selection of inputs and outputs for any model is always a challenge. It is important to work with industry experts in selecting a model that balances the needs of the users, the fundamental tradeoffs in the product, data accuracy, and data availability. This model emphasized functional characteristics but could be further refined in future work with the addition of some form or proxy of manufacturing cost. Similarly, longevity (particularly for the backlights), connectivity, and power consumption are important to many buyers and could also be added in future work. It was expressed to the authors by the expert panel that contrast ratio published numbers can be "unreliable'" as marketing departments take undue liberties despite attempts to create a standardized measure.

As the LCD market matures, the technologies across the specifications measured in the study are slowing down. As a result, LCD manufacturers are looking at other areas for differentiation such as 
display translucency, display tiling, adding computing/storage capability, or physically flexing the electronics. Adding these or other features might demonstrate greater growth or frequency of change.

Another analysis to consider would be a report on the slowing rate of change in performance characteristics and declining sales of LCD and whether there is a relationship.

Because the average living room is limited in size and most likely will not increase significantly in the next 5 years, it seems unlikely that LCD panel sizes can continue to differentiate based on size. Innovations in other areas seem likely to increase in number and magnitude. An analysis of the market looking for this phenomenon and how the manufacturers respond might be of interest.

Further analytical refinements could be applied in future work to allow for varying rates of change. In fact, the analysis used the rate of change value (gamma) from the backtesting analysis period (1997-2007) when the industry was undergoing rapid change. Including rates of change as the industry slowed down would result in less aggressive targets for Table 6. Lastly, while TFDEA is an extreme point technique that is insensitive to poor performing products, excluding special purpose products such as outdoor displays that appear obsolete by the standards of the mainstream market would improve the diagnostics such as MAD.

\section{Conclusions}

The modeling technique generated results consistent what has been observed in the LCD market in general as components become more commoditized. The innovations in the targeted attributes are slowing down and a few of these are reaching market acceptability limits (screen size) and usefulness limit (beyond the eyes ability to distinguish resolutions). Therefore, emerging features such as refresh rate, built-in interactivity, wireless connectivity, or cloud display system, will have to be adopted as a new dimension of competition. 


\section{REFERENCES}

Anderson, T. R., Daim, T. U., \& Kim, J. (2008). Technology forecasting for wireless communication. Technovation, 28(9), 602-614.

Anderson, T. R., Fare, R., Grosskopf, S., Inman, L., \& Song, X. (2002). Further examination of Moore's law with data envelopment analysis. Technological Forecasting and Social Change, 69(5), 465-477.

Bogetoft, P., \& Otto, L. (2010). Benchmarking with DEA, SFA, and R (1st ed.) , p. 367. New York, NY: Springer.

Charnes, A., Cooper, W. W., \& Rhodes, E. (1978). Measuring the efficiency of decision making units. European Journal of Operational Research, 2(6), 429-444.

Craig, Z. (2004). LCD TV panels: A history of their interface technology. Electronic Design. Retrieved from http://electronicdesign.com/article/components/lcd-tv-panels-a-historyof- their-interface-technol. Accessed on June 11, 2012.

HP. (2008). Contrast ratio - What does it really mean? Hewlett-Packard Development Company, L.P. (U.S).

Inman, O. L. (2004). Technology forecasting using data envelopment analysis. PhD dissertation. Portland State University, Portland, OR, USA.

Inman, O., Anderson, T., \& Harmon, R. (2006). Predicting U.S. jet fighter aircraft introductions from 1944 to 1982: A dogfight between regression and TFDEA. Technological Forecasting and Social Change, 73(9), 1178-1187.

Kim, J., Daim, T., \& Anderson, T. (2010). A look into the future of wireless mobile communication technologies. Technology Analysis \& Strategic Management, 22(8), 925-943.

Kim, J.-O., Kim, J.-H., \& Kim, S.-K. (2007). A comparative study of technological forecasting methods with the case of main battle tank by ranking efficient units in DEA. Korea Defense Management Analysis Society, 33(2), 61-73.

Lamb, A.-M., Anderson, T. R., \& Daim, T. (2012). Research and development target-setting difficulties addressed through the emergent method: Technology forecasting using data envelopment analysis. R \& D Management, 42(4), 15. 
Learn About LCD TV and TFT LCD Displays. (2012). Retrieved from http://www.ercservice. com/learning/fabricating-tft-lcd.html

Lim, D.-J., Anderson, T. R., \& Kim, J. (2012). Forecast of wireless communication technology: A comparative study of regression and TFDEA Model. In Technology Management for Emerging Technologies, 2012 Proceedings of PICMET' 12 . Vancouver, Canada.

Ro“ sch, D. (2005). An empirical comparison of default risk forecasts from alternative credit rating philosophies. International Journal of Forecasting, 21(1), 37-51.

Seiford, L. M. (1996, July). Data envelopment analysis: The evolution of the state of the art (1978-1995). Journal of Productivity Analysis, 7(2-3), 99-137.

Take, H. (2003). Market and technological trends in LCD TVs. Sharp Technical Journal, 85, 42-44.

Takiguchi, H. (1999). Technology-development trend of liquid crystal display. Sharp Technical Journal, 74, 511.

Tsai, B.-H. (2012). Predicting the diffusion of LCD TVs by incorporating price in the extended Gompertz Model. Technological Forecasting and Social Change, 80(1), 106-131. 